\title{
Nonlinear Contractions in 0-Complete Partial Metric Spaces
}

\author{
Abd Ghafur Bin Ahmad, ${ }^{1}$ Zaid Mohammed Fadail, 1 \\ Vesna Ćojbašić Rajić, ${ }^{2}$ and Stojan Radenović ${ }^{3}$ \\ ${ }^{1}$ School of Mathematical Sciences, Faculty of Sciences and Technology, Universiti Kebangsaan Malaysia, \\ 43600 UKM, Bangi, Selangor Darul Ehsan, Malaysia \\ ${ }^{2}$ Faculty of Economics, University of Belgrade, Kamenička 6, 11000 Beograd, Serbia \\ ${ }^{3}$ Faculty of Mechanical Engineering, University of Belgrade, Kraljice Marije 16, 11120 Beograd, Serbia
}

Correspondence should be addressed to Zaid Mohammed Fadail, zaid_fatail@yahoo.com

Received 20 March 2012; Accepted 23 May 2012

Academic Editor: Gaston Mandata N'Guerekata

Copyright ( 2012 Abd Ghafur Bin Ahmad et al. This is an open access article distributed under the Creative Commons Attribution License, which permits unrestricted use, distribution, and reproduction in any medium, provided the original work is properly cited.

Using the setting of 0 -complete partial metric spaces, some common fixed point results of maps that satisfy the nonlinear contractive conditions are obtained. These results generalize and improve the existing fixed point results in the literature in the sense that weaker conditions are used. An example shows how our result can be used when the corresponding result in standard metric cannot.

\section{Introduction and Preliminaries}

Matthews [1] generalized the concept of a metric space by introducing partial metric spaces. Based on the notion of partial metric spaces, Matthews [1, 2], Oltra and Valero [3], Ilić et al. $[4,5]$ obtained some fixed point theorems for mappings satisfying different contractive conditions. Recently, Abdeljawad et al. [6] proved one fixed point result for generalized contraction principle with control functions on partial metric spaces. For some new results on partial metric and cone metric spaces, see [1-27].

The aim of this paper is to continue the study of common fixed points of mappings but now in 0-complete partial metric spaces, under nonlinear generalized contractive conditions.

Consistent with Matthews [1, 2], O'Neill [21, 22], and Oltra et al. [23], the following definitions and results will be needed throughout this paper.

Definition 1.1. A partial metric on a nonempty set $X$ is a function $p: X \times X \rightarrow R^{+}$such that for all $x, y, z \in X$ :

$$
\text { (p1) } x=y \Leftrightarrow p(x, x)=p(x, y)=p(y, y),
$$


(p2) $p(x, x) \leq p(x, y)$,

(p3) $p(x, y)=p(y, x)$,

(p4) $p(x, z) \leq p(x, y)+p(y, z)-p(y, y)$.

A partial metric space is a pair $(X, p)$ such that $X$ is a nonempty set and $p$ is a partial metric on $X$.

For a partial metric $p$ on $X$, the function $p^{s}: X \times X \rightarrow R^{+}$given by

$$
p^{s}(x, y)=2 p(x, y)-p(x, x)-p(y, y)
$$

is a (usual) metric on $X$. Each partial metric $p$ on $X$ generates a $T_{0}$ topology $\tau_{p}$ on $X$ with a base of the family of open $p$-balls $\left\{B_{p}(x, \varepsilon): x \in X, \varepsilon>0\right\}$, where $B_{p}(x, \varepsilon)=\{y \in X: p(x, y)<$ $p(x, x)+\varepsilon\}$ for all $x \in X$ and $\varepsilon>0$.

Definition 1.2 (see $[1,20])$. (i) A sequence $\left\{x_{n}\right\}$ in a partial metric space $(X, p)$ converges to $x \in X$ if and only if $p(x, x)=\lim _{n \rightarrow+\infty} p\left(x_{n}, x\right)$.

(ii) a sequence $\left\{x_{n}\right\}$ in a partial metric space $(X, p)$ is called 0 -Cauchy if $\lim _{n, m \rightarrow+\infty} p\left(x_{n}\right.$, $\left.x_{m}\right)=0$.

(iii) a partial metric space $(X, p)$ is said to be 0 -complete if every 0 -Cauchy sequence $\left\{x_{n}\right\}$ in $X$ converges, with respect to $\tau_{p}$, to a point $x \in X$ such that $p(x, x)=0$. In this case, $p$ is a 0 -complete partial metric on $X$.

Remark 1.3. (1) (see [20]) Clearly, a limit of a sequence in a partial metric space does not need to be unique. Moreover, the function $p(\cdot, \cdot)$ does not need to be continuous in the sense that $x_{n} \rightarrow x$ and $y_{n} \rightarrow y$ implies $p\left(x_{n}, y_{n}\right) \rightarrow p(x, y)$. For example, if $X=[0,+\infty)$ and $p(x, y)=$ $\max \{x, y\}$ for $x, y \in X$, then for $\left\{x_{n}\right\}=\{1\}, p\left(x_{n}, x\right)=x=p(x, x)$ for each $x \geq 1$ and so, for example, $x_{n} \rightarrow 2$ and $x_{n} \rightarrow 3$ when $n \rightarrow \infty$.

(2) (see [6]) However, if $p\left(x_{n}, x\right) \rightarrow p(x, x)=0$, then $p\left(x_{n}, y\right) \rightarrow p(x, y)$ for all $y \in X$.

Assertions similar to the following lemma were used (and proved) in the course of proofs of several fixed point results in various papers $[8,9,20,28]$.

Lemma 1.4. Let $(X, p)$ be a partial metric space and let $\left\{y_{n}\right\}$ be a sequence in $X$ such that $p\left(y_{n}, y_{n+1}\right)$ is nonincreasing and that

$$
\lim _{n \rightarrow+\infty} p\left(y_{n}, y_{n+1}\right)=0
$$

If $\left\{y_{2 n}\right\}$ is not a 0-Cauchy sequence in $(X, p)$, then there exist $\varepsilon>0$ and two sequences $\left\{m_{k}\right\}$ and $\left\{n_{k}\right\}$ of positive integers such that $m_{k}>n_{k}>k$ and the following four sequences tend to $\varepsilon^{+}$when $k \rightarrow+\infty$ :

$$
p\left(y_{2 m_{k}}, y_{2 n_{k}}\right), p\left(y_{2 m_{k}}, y_{2 n_{k}+1}\right), p\left(y_{2 m_{k}-1}, y_{2 n_{k}}\right), p\left(y_{2 m_{k}-1}, y_{2 n_{k}+1}\right)
$$

Definition 1.5 (see [29]). Let $f$ and $g$ be self-maps of a set $X$. If $w=f x=g x$ for some $x \in X$, then $x$ is called a coincidence point of $f$ and $g$, and $w$ is called a point of coincidence of $f$ and $g$. The pair $f, g$ of self-maps is weakly compatible if they commute at their coincidence points. 
The following lemma is Proposition 1.4 of [29].

Lemma 1.6. Let $f$ and $g$ be weakly compatible self-maps of a set $X$. If $f$ and $g$ have a unique point of coincidence $w=f x=g x$, then $w$ is the unique common fixed point of $f$ and $g$.

Definition 1.7 (see [30]). The following two classes of mappings are defined as $\Psi=\{\psi \mid \psi$ : $[0, \infty) \rightarrow[0, \infty)$ is a nondecreasing right continuous function such that $\lim _{n \rightarrow+\infty} \psi^{n}(t)=0$ for all $t>0$, and $\Phi=\{\psi \mid \psi:[0, \infty) \rightarrow[0, \infty)$ is a nondecreasing function such that $\lim _{n \rightarrow+\infty} \psi^{n}(t)=0$ for all $t>0$.

It is clear for the function

$$
\psi(t)= \begin{cases}\frac{1}{3} t, & 0 \leq t<1 \\ \frac{1}{2}, & t=1 \\ \frac{2}{3} t, & t>1\end{cases}
$$

that $\psi \in \Phi$ but $\psi \notin \Psi$.

Lemma 1.8 (see [19]). If $\psi \in \Phi$, then $\psi(t)<t$ for all $t>0$ and $\psi(0)=0$.

\section{Common Fixed Point Results}

In this section, we obtain some common fixed point results defined on 0-complete partial metric spaces.

Theorem 2.1. Let $(X, p)$ be a partial metric space and $T, f$ be mappings on $X$ with $T X \subset f X$. Assume that

$$
p(T x, T y) \leq \psi\left(\max \left\{p(f x, f y), p(f x, T x), p(f y, T y), \frac{p(f x, T y)+p(f y, T x)}{2}\right\}\right)
$$

for all $x, y \in X$, where $\psi \in \Psi$. If $T X$ or $f X$ is a 0 -complete subspace of $X$, then $T$ and $f$ have a unique point of coincidence. Moreover, if $T$ and $f$ are weakly compatible, then $T$ and $f$ have a unique common fixed point.

Proof. First, we prove that $T$ and $f$ have a unique point of coincidence (if it exists). If $y \in X$ with $y=T u=f u$ and $z \in X$ with $z=T s=f s$, we assume $z \neq y$. Applying (2.1) we have

$$
\begin{aligned}
p(y, z) & =p(T u, T s) \\
& \leq \psi\left(\max \left\{p(f u, f s), p(f u, T u), p(f s, T s), \frac{p(f u, T s)+p(f s, T u)}{2}\right\}\right) \\
& =\psi\left(\max \left\{p(y, z), p(y, y), p(z, z), \frac{p(y, z)+p(z, y)}{2}\right\}\right) \\
& =\psi(p(y, z)) \quad(\text { by }(p 2)) \\
& <p(y, z) .
\end{aligned}
$$

This implies a contradiction, so we conclude that $z=y$. 
Now, consider the sequence $\left\{x_{n}\right\} \subset X$ defined by $x_{0} \in X$ and $T x_{n}=f x_{n+1}$. Consider the two possible cases:

(i) $p\left(T x_{n+1}, T x_{n}\right)=0$ for some $n \in \mathbb{N}$.

In this case $T x_{n}=f x_{n}(=y$ a point of coincidence). Because of Lemma 1.6 (unique point of coincidence and weakly compatible mappings) we have a unique common fixed point.

(iii) $p\left(T x_{n+1}, T x_{n}\right)>0$ for every $n \in \mathbb{N}$.

Applying (2.1) with $x=x_{n+1}$ and $y=x_{n}$, we have,

$$
\begin{aligned}
p\left(T x_{n+1}, T x_{n}\right) \leq & \psi\left(\operatorname { m a x } \left\{p\left(f x_{n+1}, f x_{n}\right), p\left(f x_{n+1}, T x_{n+1}\right), p\left(f x_{n}, T x_{n}\right),\right.\right. \\
& \left.\left.\frac{p\left(f x_{n+1}, T x_{n}\right)+p\left(f x_{n}, T x_{n+1}\right)}{2}\right\}\right) \\
= & \psi\left(\operatorname { m a x } \left\{p\left(T x_{n}, T x_{n-1}\right), p\left(T x_{n}, T x_{n+1}\right), p\left(T x_{n-1}, T x_{n}\right),\right.\right. \\
& =\psi\left(\max \left\{p\left(T x_{n}, T x_{n-1}\right), p\left(T x_{n}, T x_{n+1}\right), \frac{p\left(T x_{n}, T x_{n}\right)+p\left(T x_{n-1}, T x_{n+1}\right)}{2}\right\}\right) \\
\leq & \psi\left(\operatorname { m a x } \left\{p\left(T x_{n-1}, T x_{n+1}\right)\right.\right. \\
2 & \left.\left.\left.T x_{n-1}\right), p\left(T x_{n}, T x_{n+1}\right), \frac{p\left(T x_{n-1}, T x_{n}\right)+p\left(T x_{n}, T x_{n+1}\right)}{2}\right\}\right) \\
= & \psi\left(\max \left\{p\left(T x_{n}, T x_{n-1}\right), p\left(T x_{n}, T x_{n+1}\right)\right\}\right) .
\end{aligned}
$$

If $p\left(T x_{n+1}, T x_{n}\right)$ is a maximum, then we have

$$
p\left(T x_{n+1}, T x_{n}\right) \leq \psi\left(p\left(T x_{n}, T x_{n+1}\right)\right)<p\left(T x_{n}, T x_{n+1}\right),
$$

which is a contradiction. So, we conclude that the maximum is $p\left(T x_{n}, T x_{n-1}\right)$. Now, we have the following:

$$
p\left(T x_{n+1}, T x_{n}\right) \leq \psi\left(p\left(T x_{n}, T x_{n-1}\right)\right)<p\left(T x_{n}, T x_{n-1}\right)
$$

It follows from (2.5) that the sequence $p\left(T x_{n+1}, T x_{n}\right)$ is monotone decreasing. According to the properties of function $\psi$, it follows

$$
\begin{aligned}
p\left(T x_{n+1}, T x_{n}\right) & \leq \psi\left(p\left(T x_{n}, T x_{n-1}\right)\right) \\
& \leq \psi^{2}\left(p\left(T x_{n-1}, T x_{n-2}\right)\right) \leq \cdots \leq \psi^{n}\left(p\left(T x_{1}, T x_{0}\right)\right) \longrightarrow 0
\end{aligned}
$$

when $n \rightarrow+\infty$. Therefore, $\lim _{n \rightarrow+\infty} p\left(T x_{n+1}, T x_{n}\right)=0$. 
Next, we prove that $\left\{T x_{n}\right\}$ is a 0 -Cauchy sequence in the space $(X, p)$. It is sufficient to show that $\left\{T x_{2 n}\right\}$ is a 0-Cauchy sequence. Assume the opposite. Then using Lemma 1.4 we get that there exist $\varepsilon>0$ and two sequences $\{m(k)\}$ and $\{n(k)\}$ of positive integers and sequences

$$
p\left(y_{2 m_{k}}, y_{2 n_{k}}\right), p\left(y_{2 m_{k}}, y_{2 n_{k}+1}\right), p\left(y_{2 m_{k}-1}, y_{2 n_{k}}\right), p\left(y_{2 m_{k}-1}, y_{2 n_{k}+1}\right)
$$

all tend to $\varepsilon^{+}$when $k \rightarrow+\infty$. Applying condition (2.1) to elements $x=x_{2 m(k)}$ and $y=x_{2 n(k)+1}$ and putting $y_{n}=T x_{n}=f x_{n+1}$ for each $n \geq 0$, we get that

$$
\begin{aligned}
& p\left(T x_{2 m(k)}, T x_{2 n(k)+1}\right) \\
&= p\left(y_{2 m(k)}, y_{2 n(k)+1}\right) \\
& \leq \psi\left(\operatorname { m a x } \left\{p\left(f x_{2 m(k)}, f x_{2 n(k)+1}\right), p\left(f x_{2 m(k)}, T x_{2 m(k)}\right), p\left(f x_{2 n(k)+1}, T x_{2 n(k)+1}\right),\right.\right. \\
&\left.\left.\frac{p\left(f x_{2 m(k)}, T x_{2 n(k)+1}\right)+p\left(f x_{2 n(k)+1}, T x_{2 m(k)}\right)}{2}\right\}\right) \\
&=\left(\operatorname { m a x } \left\{p\left(y_{2 m(k)-1}, y_{2 n(k)}\right), p\left(y_{2 m(k)-1}, y_{2 m(k)}\right), p\left(y_{2 n(k)}, y_{2 n(k)+1}\right),\right.\right. \\
&\left.\left.\frac{p\left(y_{2 m(k)-1}, y_{2 n(k)+1}\right)+p\left(y_{2 n(k)}, y_{2 m(k)}\right)}{2}\right\}\right) .
\end{aligned}
$$

When $k \rightarrow+\infty$, we have

$$
\begin{aligned}
\max & \left\{p\left(y_{2 m(k)-1}, y_{2 n(k)}\right), p\left(y_{2 m(k)-1}, y_{2 m(k)}\right), p\left(y_{2 n(k)}, y_{2 n(k)+1}\right),\right. \\
& \left.\frac{p\left(y_{2 m(k)-1}, y_{2 n(k)+1}\right)+p\left(y_{2 n(k)}, y_{2 m(k)}\right)}{2}\right\} \\
\longrightarrow & \max \left\{\varepsilon^{+}, 0,0, \frac{1}{2}\left(\varepsilon^{+}+\varepsilon^{+}\right)\right\}=\varepsilon^{+}
\end{aligned}
$$

Using properties of $\psi$, we obtain a contradiction $\varepsilon \leq \psi(\varepsilon)<\varepsilon$, since $\varepsilon>0$.

This shows that $\left\{T x_{2 n}\right\}$ is a 0 -Cauchy sequence in the space $(X, p)$ and hence $\left\{T x_{n}\right\}$ is a 0 -Cauchy sequence in $(X, p)$. If we suppose that $T X$ is a 0 -complete subspace of $(X, p)$, then there exists $y \in T X \subset f X$ such that

$$
p(y, y)=\lim _{n \rightarrow+\infty} p\left(T x_{n}, y\right)=\lim _{n \rightarrow+\infty} p\left(f x_{n}, y\right)=\lim _{n, m \rightarrow+\infty} p\left(T x_{n}, T x_{m}\right)=0 .
$$

If $f X$ is a 0 -complete subspace of $(X, p)$ with $y \in f X,(2.10)$ also holds. 
Let $u \in X$ and $y=f u$. We show that $y$ is a point of coincidence of $T$ and $f$. Suppose that $p(T u, f u)>0$. We have

$$
p\left(T x_{n}, T u\right) \leq \psi\left(\max \left\{p\left(f x_{n}, f u\right), p\left(f x_{n}, T x_{n}\right), p(f u, T u), \frac{p\left(f x_{n}, T u\right)+p\left(f u, T x_{n}\right)}{2}\right\}\right) .
$$

As $n \rightarrow+\infty$, we have $p\left(f x_{n}, f u\right) \rightarrow 0, p\left(f x_{n}, T x_{n}\right) \rightarrow 0$ and by Remark 1.3 (2) $\left(p\left(f x_{n}, T u\right)+p\left(f u, T x_{n}\right)\right) / 2 \rightarrow p(f u, T u) / 2$. Since $p(f u, T u)>0$, there exists $n_{0} \in \mathbb{N}$ such that for every $n>n_{0}$ we have $p\left(f x_{n}, f u\right)<(1 / 2) p(f u, T u)$ and $p\left(f x_{n}, T x_{n}\right)<(1 / 2) p(f u, T u)$. Now, for $n>n_{0}$, we obtain

$$
p(f u, T u) \leq p\left(f u, f x_{n+1}\right)+p\left(T x_{n}, T u\right) \leq p\left(f u, f x_{n+1}\right)+\psi(p(f u, T u))
$$

or

$$
p(f u, T u) \leq p\left(f u, f x_{n+1}\right)+\psi(p(f u, T u))
$$

As $n \rightarrow+\infty$ we have a contradiction:

$$
p(f u, T u) \leq \psi(p(f u, T u))<p(f u, T u)
$$

This implies $p(T u, f u)=0$, that is, $T u=f u$. Hence, $T$ and $f$ have a (unique) point of coincidence. From Lemma 1.6 follows that this is a unique common fixed point of $T$ and $f$.

Remark 2.2. Assumption about right continuity of the function is only used in the proof that $\left\{T x_{n}\right\}$ is a 0 -Cauchy sequence.

In the following theorem we consider a weaker assumption for the function $\psi$. As a compensation we assume a bit stronger contractive condition.

Theorem 2.3. Let $(X, p)$ be a partial metric space and $T, f$ be mappings on $X$ with $T X \subset f X$. Assume that

$$
p(T x, T y) \leq \psi\left(\max \left\{p(f x, f y), p(f x, T x), p(f y, T y), \frac{p(f x, T y)}{2}\right\}\right)
$$

for all $x, y \in X$, where $\psi \in \Phi$. If $T X$ or $f X$ is a 0 -complete subspace of $X$, then $T$ and $f$ have a unique point of coincidence. Moreover, if $T$ and $f$ are weakly compatible, then $T$ and $f$ have a unique common fixed point.

Proof. We can prove that $T$ and $f$ have a unique point of coincidence in a similar way like in Theorem 2.1. If we consider the sequence $\left\{x_{n}\right\} \subset X$ defined by $x_{0} \in X$ and $T x_{n}=f x_{n+1}$, we used Theorem 2.1 to show $\lim _{n \rightarrow+\infty} p\left(T x_{n+1}, T x_{n}\right)=0$.

Here, we only prove that $\left\{T x_{n}\right\}$ is a 0 -Cauchy sequence in the space $(X, p)$ by using induction. Let us denote $y_{n}=T x_{n}=f x_{n+1}$ for each $n \geq 0$, We have $p\left(y_{n}, y_{n+1}\right) \rightarrow 0$, as 
$n \rightarrow+\infty$. For $\varepsilon>0$ there exists $n(\varepsilon)$ such that for every $n>n(\varepsilon)$ we have $p\left(y_{n}, y_{n+1}\right)<\varepsilon-\psi(\varepsilon)$. Assuming that for some $n>n(\varepsilon)$ and $k \in \mathbb{N}$ it holds that $p\left(y_{n}, y_{n+k}\right)<\varepsilon$ and we need to prove that $p\left(y_{n}, y_{n+k+1}\right)<\varepsilon$.

We have

$$
\begin{aligned}
& p\left(y_{n}, y_{n+k+1}\right) \leq p\left(y_{n}, y_{n+1}\right)+p\left(y_{n+1}, y_{n+k+1}\right) \\
& p\left(y_{n+1}, y_{n+k+1}\right) \\
& =p\left(T x_{n+1}, T x_{n+k+1}\right) \\
& \leq \psi\left(\max \left\{p\left(f x_{n+1}, f x_{n+k+1}\right), p\left(f x_{n+1}, T x_{n+1}\right), p\left(f x_{n+k+1}, T x_{n+k+1}\right), \frac{p\left(f x_{n+1}, T x_{n+k+1}\right)}{2}\right\}\right) \\
& =\psi\left(\max \left\{p\left(y_{n}, y_{n+k}\right), p\left(y_{n}, y_{n+1}\right), p\left(y_{n+k}, y_{n+k+1}\right), \frac{p\left(y_{n}, y_{n+k+1}\right)}{2}\right\}\right) \\
& \leq \psi\left(\max \left\{p\left(y_{n}, y_{n+k}\right), p\left(y_{n}, y_{n+1}\right), p\left(y_{n+k}, y_{n+k+1}\right), \frac{p\left(y_{n}, y_{n+k}\right)+p\left(y_{n+k}, y_{n+k+1}\right)}{2}\right\}\right) \\
& \leq \psi\left(\max \left\{\varepsilon, \varepsilon-\psi(\varepsilon), \varepsilon-\psi(\varepsilon), \frac{\varepsilon+\varepsilon-\psi(\varepsilon)}{2}\right\}\right)=\psi(\varepsilon) .
\end{aligned}
$$

Then (2.16) becomes $p\left(y_{n}, y_{n+k+1}\right) \leq p\left(y_{n}, y_{n+1}\right)+p\left(y_{n+1}, y_{n+k+1}\right)<\varepsilon-\psi(\varepsilon)+\psi(\varepsilon)=$ $\varepsilon$. This shows that $\left\{T x_{n}\right\}$ is a 0 -Cauchy sequence in $(X, p)$. Further, proof is similar as in Theorem 2.1, so we omit it.

Corollary 2.4. Let $(X, p)$ be a partial metric space and let $T: X \rightarrow X$ be a map such that

$$
p(T x, T y) \leq \psi\left(\max \left\{p(x, y), p(x, T x), p(y, T y), \frac{p(x, T y)+p(y, T x)}{2}\right\}\right)
$$

for all $x, y \in X$, where $\psi \in \Psi$. If TX is a 0 -complete subspace of $X$, then $T$ has a unique fixed point.

Proof. It follows from Theorem 2.1 by taking $f=i_{X}$ (the identity map).

Corollary 2.5. Let $(X, p)$ be a partial metric space and let $T: X \rightarrow X$ be a map such that

$$
p(T x, T y) \leq \psi\left(\max \left\{p(x, y), p(x, T x), p(y, T y), \frac{p(x, T y)}{2}\right\}\right)
$$

for all $x, y \in X$, where $\psi \in \Phi$. If $T X$ is a 0 -complete subspace of $X$, then $T$ has a unique fixed point. Proof. It follows from Theorem 2.3 by taking $f=i_{X}$ (the identity map). 
Corollary 2.6. Let $(X, p)$ be a partial metric space and let $T, f$ be mappings on $X$ with $T X \subset f X$. Assume that

$$
p(T x, T y) \leq \lambda \max \left\{p(f x, f y), p(f x, T x), p(f y, T y), \frac{p(f x, T y)+p(f y, T x)}{2}\right\}
$$

for all $x, y \in X$, where $\lambda \in[0,1)$. If $T X$ or $f X$ is a 0 -complete subspace of $X$, then $T$ and $f$ have $a$ unique point of coincidence. Moreover, if $T$ and $f$ are weakly compatible, then $T$ and $f$ have a unique fixed point.

Proof. It follows from Theorem 2.1 by taking $\psi(t)=\lambda t$, where $\lambda \in[0,1)$.

Corollary 2.7. Let $(X, p)$ be a partial metric space and let $T, f$ be mappings on $X$ with $T X \subset f X$. Assume that

$$
\begin{aligned}
p(T x, T y) \leq & a_{1} p(f x, f y)+a_{2} p(f x, T x)+a_{3} p(f y, T y) \\
& +a_{4}(p(f x, T y)+p(f y, T x))
\end{aligned}
$$

for all $x, y \in X$, where $a_{1}, a_{2}, a_{3}, a_{4} \geq 0$ and $a_{1}+a_{2}+a_{3}+2 a_{4} \in[0,1)$. If $T X$ or $f X$ is a 0-complete subspace of $X$, then $T$ and $f$ have a unique point of coincidence. Moreover, if $T$ and $f$ are weakly compatible, then $T$ and $f$ have a unique fixed point.

Proof. It follows from Corollary 2.6 by noting that

$$
\begin{aligned}
& a_{1} p(f x, f y)+a_{2} p(f x, T x)+a_{3} p(f y, T y)+a_{4}(p(f x, T y)+p(f y, T x)) \\
& \quad \leq\left(a_{1}+a_{2}+a_{3}+2 a_{4}\right) \max \left\{p(f x, f y), p(f x, T x), p(f y, T y), \frac{p(f x, T y)+p(f y, T x)}{2}\right\}
\end{aligned}
$$

Corollary 2.8. Let $(X, p)$ be a partial metric space and let $T, f$ be mappings on $X$ with $T X \subset f X$. Assume that

$$
p(T x, T y) \leq \lambda p(f x, f y)
$$

for all $x, y \in X$, where $\lambda \in[0,1)$. If $T X$ or $f X$ is a 0 -complete subspace of $X$, then $T$ and $f$ have $a$ unique point of coincidence. Moreover, if $T$ and $f$ are weakly compatible, then $T$ and $f$ have a unique fixed point.

Proof. It follows from Corollary 2.7.

From Corollary 2.8 follows the theorem proved by Jungck [31], where we consider a 0 -complete partial metric space instead of a complete metric space, under the assumption that $T$ and $f$ are commuting mappings. 
Corollary 2.9. Let $(X, p)$ be a 0 -complete partial metric space and $T: X \rightarrow X$ be a map such that

$$
p(T x, T y) \leq \psi(p(x, y))
$$

for all $x, y \in X$, where $\psi \in \Phi$. If $T X$ is a closed subspace of $X$, then $T$ has a unique fixed point.

Proof. It follows from Theorem 2.3 and Corollary 2.5. by taking $f=i_{X}$ (the identity map).

Under a weaker assumption for the function $\psi$, from Corollary 2.9 follows the theorem proved by Boyd and Wong [32] where we consider a partial metric instead of a standard metric.

From Corollary 2.7 we deduce the following corollaries, which are extensions of some well-known theorems.

Corollary 2.10. Let $(X, p)$ be a 0-complete partial metric space and let $T: X \rightarrow X$ be a map such that

$$
p(T x, T y) \leq \lambda p(x, y)
$$

for all $x, y \in X$, where $\lambda \in[0,1)$. Then $T$ has a unique fixed point.

This corollary is an extension of Banach contraction theorem on a 0-complete partial metric space. This corollary is already mentioned in Matthews [2] for a complete partial metric space, but is true for a 0-complete partial metric spaces.

Corollary 2.11. Let $(X, p)$ be a 0-complete partial metric space and let $T: X \rightarrow X$ be a map such that

$$
p(T x, T y) \leq \lambda(p(x, T x)+p(y, T y))
$$

for all $x, y \in X$, where $\lambda \in[0,(1 / 2))$. Then $T$ has a unique fixed point.

This corollary is extension of Kannan theorem [33] (4) on a 0-complete partial metric spaces.

Corollary 2.12. Let $(X, p)$ be a 0-complete partial metric space and let $T: X \rightarrow X$ be a map such that

$$
p(T x, T y) \leq a_{1} p(x, y)+a_{2} p(x, T x)+a_{3} p(y, T y)
$$

for all $x, y \in X$, where $a_{1}, a_{2}, a_{3} \geq$ and $a_{1}+a_{2}+a_{2} \in[0,1)$. Then $T$ has a unique fixed point.

This corollary is extension of Reich theorem [33] (8) on a 0-complete partial metric spaces. 
Corollary 2.13. Let $(X, p)$ be a 0-complete partial metric space and let $T: X \rightarrow X$ be a map such that

$$
p(T x, T y) \leq \lambda(p(x, T y)+p(y, T x))
$$

for all $x, y \in X$, where $\lambda \in[0,(1 / 2))$. Then $T$ has a unique fixed point.

This corollary is extension of Chatterjea theorem [33] (11) on a 0-complete partial metric spaces.

Corollary 2.14. Let $(X, p)$ be a 0 -complete partial metric space and let $T: X \rightarrow X$ be a map such that at least one of the following is true

$$
\begin{aligned}
& p(T x, T y) \leq a_{1} p(x, T x) \\
& p(T x, T y) \leq a_{2}(p(x, T x)+p(y, T y)) \\
& p(T x, T y) \leq a_{3}(p(x, T y)+p(y, T x))
\end{aligned}
$$

for all $x, y \in X$, where $a_{1} \in[0,1), a_{2}, a_{3} \in[0,(1 / 2))$. Then $T$ has a unique fixed point.

This corollary is extension of Zamfirescu theorem [33] (19) on a 0-complete partial metric spaces.

We demonstrate the use of Theorem 2.1 with the help of the following example.

Example 2.15. Let $(X, p)=(\mathbb{Q} \cap[0,1), p)$, where $\mathbb{Q}$ denotes the set of rational numbers and $p$ is given by $p(x, y)=\max \{x, y\}$. Then $(X, p)$ is a 0 -complete partial metric space which is not complete. Suppose that $T, f: X \rightarrow X$ are such that $T x=x^{2} /(1+x), f x=x$ for all $x \in X$ and

$$
\psi(t)= \begin{cases}t^{2}, & t>\frac{1}{5} \\ \frac{1}{5} t, & t \leq \frac{1}{5} .\end{cases}
$$

Then $\psi \in \Psi$. Without loss of generality assume that $x<y$. Then $x^{2} /(1+x)<y /(1+y), x^{2} /(1+$ $x) \leq x$ and $\left(y^{2} /(1+y)\right) \leq y$. From (2.1) follows

$$
\begin{gathered}
L=\max \left\{\frac{x^{2}}{1+x}, \frac{y^{2}}{1+y}\right\}=\frac{y^{2}}{1+y^{\prime}}, \\
R=\psi\left(\max \left\{p(x, y), p\left(x, \frac{x^{2}}{1+x}\right), p\left(y, \frac{y^{2}}{1+y}\right), \frac{p\left(x, y^{2} /(1+y)\right)+p\left(y, x^{2} /(1+x)\right)}{2}\right\}\right) \\
=\psi\left(\max \left\{y, x, y, \frac{\max \left(x, y^{2} /(1+y)\right)+\max \left(y, x^{2} /(1+x)\right)}{2}\right\}\right) \leq \psi(y)
\end{gathered}
$$


and so $y^{2} /(1+y) \leq \psi(y)$. If $y \leq 1 / 5$, then we have $y^{2} /(1+y) \leq y / 5$ (this is true because $\left.y^{2} /(1+y) \leq y^{2} \leq y / 5\right)$. If $y>1 / 5$ then we have $y^{2} /(1+y) \leq y^{2}$, which is true. It follows that $T$ has a unique fixed point.

On the other hand, consider the same problem in the standard metric $d(x, y)=|x-y|$ and take $x=0.10, y=0.30$. Then, from (2.1) follows $L=0.009-0.069=0.06$ and

$$
\begin{aligned}
R & =\psi\left(\max \left\{0.10-0.30,0.10-0.009,0.30-0.069, \frac{0.10-0.069+0.30-0.009}{2}\right\}\right) \\
& =\psi(0.231)=0.053 .
\end{aligned}
$$

Hence $L \leq R$ does not hold and the existence of a unique fixed point cannot be obtained.

Remark 2.16. Note that Theorem 2.1 improves [12, Theorem 1 and Corollary 1], [25, Theorem 3, Corollaries 1 and 2 and Theorem 4], and [13, Corollary 2.3] since our assumptions are weaker than the assumptions from $[12,13,25]$ in several places.

Finally, it is worth to notice that all new results in recently papers $[7,10,15,20,27]$ are true if partial metric space $(X, p)$ is 0 -complete instead complete.

\section{Acknowledgments}

The authors are thankful to the referees for their remarks which helped to improve the presentation of the paper. The authors (first and second) would like to acknowledge the financial support received from Universiti Kebangsaan Malaysia under the research grant OUP-UKM-FST-2012. The third and the fourth authors are thankful to the Ministry of Science and Technological Development of Serbia.

\section{References}

[1] S. G. Matthews, "Partial metric topology," in Proceedings of the 8th Summer Conference on General Topology and Applications, vol. 728, pp. 183-197, Annals of the New York Academy of Sciences.

[2] S. G. Matthews, "Partial metric topology," Research Report 212, Department of Computer Science, University of Warwick, 1992.

[3] S. Oltra and O. Valero, "Banach's fixed point theorem for partial metric spaces," Rendiconti dell'Istituto di Matematica dell'Università di Trieste, vol. 36, no. 1-2, pp. 17-26, 2004.

[4] D. Ilić, V. Pavlović, and V. Rakočević, "Some new extensions of Banach's contraction principle to partial metric space," Applied Mathematics Letters, vol. 24, no. 8, pp. 1326-1330, 2011.

[5] D. Ilić, V. Pavlović, and V. Rakočević, "Extensions of the Zamfirescu theorem to partial metric spaces," Mathematical and Computer Modelling, vol. 55, no. 3-4, pp. 801-809, 2012.

[6] T. Abdeljawad, E. Karapinar, and K. Taş, "Existence and uniqueness of a common fixed point on partial metric spaces," Applied Mathematics Letters, vol. 24, no. 11, pp. 1900-1904, 2011.

[7] M. Abbas, T. Nazir, and S. Romaguera, "Fixed pooint results for generalized cyclic contrac-tion mappings in partial metric spaces," Revista de la Real Academia de Ciencias Exactas, Fisicas y Naturales. Serie A. In press.

[8] T. Abdeljawad, "Fixed points for generalized weakly contractive mappings in partial metric spaces," Mathematical and Computer Modelling, vol. 54, no. 11-12, pp. 2923-2927, 2011.

[9] T. Abdeljawad, E. Karapinar, and K. Taş, "A generalized contraction principle with control functions on partial metric spaces," Computers \& Mathematics with Applications. An International Journal, vol. 63, no. 3, pp. 716-719, 2012. 
[10] R. P. Agarwal, M. A. Alghamdi, and N. Shahzad, "Fixed point theory for cyclic generalized contractions in partial metric spaces," Fixed Point Theory and Applications, vol. 2012, article 40, 2012.

[11] I. Altun and A. Erduran, "Fixed point theorems for monotone mappings on partial metric spaces," Fixed Point Theory and Applications, vol. 2011, Article ID 508730, 10 pages, 2011.

[12] I. Altun, F. Sola, and H. Simsek, "Generalized contractions on partial metric spaces," Topology and its Applications, vol. 157, no. 18, pp. 2778-2785, 2010.

[13] L. Ćirić, B. Samet, H. Aydi, and C. Vetro, "Common fixed points of generalized contractions on partial metric spaces and an application," Applied Mathematics and Computation, vol. 218, no. 6, pp. 2398-2406, 2011.

[14] D. Đukić, Z. Kadelburg, and S. Radenović, "Fixed points of Geraghty-type mappings in various generalized metric spaces," Abstract and Applied Analysis, vol. 2011, Article ID 561245, 13 pages, 2011.

[15] N. Hussain, Z. Kadelburg, and S. Radenović, "Comparison functions and fixed point results in partial metric spaces," Abstrac and Applied Analysis, vol. 2012, Article ID 605781, 15 pages.

[16] Z. M. Fadail and A. G. B. Ahmad, "Coupled fixed point theorems of single-valued mapping for cdistance in cone metric spaces," Journal of Applied Mathematics, vol. 2012, Article ID 246516, 20 pages, 2012.

[17] Z. M. Fadail, A. G. B. Ahmad, and Z. Golubovic, "Fixed Point theorems of single-valued mapping for c-distance in cone metric spaces," Abstract and Applied Analysis, vol. 2012, Article ID 826815, 10 pages, 2012.

[18] E. Karapinar and M. Erhan, "Fixed point theorems for operators on partial metric spaces," Applied Mathematics Letters, vol. 24, no. 11, pp. 1894-1899, 2011.

[19] J. Matkowski, "Fixed point theorems for mappings with a contractive iterate at a point," Proceedings of the American Mathematical Society, vol. 62, no. 2, pp. 344-348, 1977.

[20] H. K. Nashine, Z. Kadelburg, and S. Radenović, "Common fixed point theorems for weakly isotone increasing mappings in ordered partial metric spaces," Mathematical and Computer Modelling. In press.

[21] S. J. O'Neill, "Partial metrics, valuations and domain theory," in Proceedings of the 11th Summer Conference on General Topology and Applications, vol. 806, pp. 304-315, Annals of the New York Academy of Sciences, 1996.

[22] S. J. ONeill, “Two topologies are better than one," Tech. Rep., University of Warwick, Conventry, UK, 1995, http:/ / www.dcs.warwick.ac.uk/reports/283.html.

[23] S. Oltra, S. Romaguera, and E. A. Sánchez-Pérez, "Bicompleting weightable quasi-metric spaces and partial metric spaces," Rendiconti del Circolo Matematico di Palermo. Serie II, vol. 51, no. 1, pp. 151-162, 2002.

[24] D. Paesano and P. Vetro, "Suzuki's type characterizations of completeness for partial metric spaces and fixed points for partially ordered metric spaces," Topology and its Applications, vol. 159, no. 3, pp. 911-920, 2012.

[25] S. Romaguera, "Fixed point theorems for generalized contractions on partial metric spaces," Topology and its Applications, vol. 159, no. 1, pp. 194-199, 2012.

[26] S. Romaguera, "A Kirk type characterization of completeness for partial metric spaces," Fixed Point Theory and Applications, vol. 2010, Article ID 493298, 6 pages, 2010.

[27] B. Samet, M. Rajovi, R. Lazovi, and R. Stoiljkovi, "Common fixed point results for nonlinear contractions in ordered partial metric spaces," Fixed Point Theory and Applications, vol. 2011, article 71, 2011.

[28] S. Radenović, Z. Kadelburg, D. Jandrli, and A. Jandrli, "Some results on weakly con-tractive maps," Bulletin of the Iranian Mathematical Society. In press.

[29] M. Abbas and G. Jungck, "Common fixed point results for noncommuting mappings without continuity in cone metric spaces," Journal of Mathematical Analysis and Applications, vol. 341, no. 1, pp. 416-420, 2008.

[30] I. A. Rus, Generalized Contractions and Applications, Cluj University Press, Cluj-Napoca, Romania, 2001.

[31] G. Jungck, "Commuting mappings and fixed points," The American Mathematical Monthly, vol. 83, no. 4, pp. 261-263, 1976.

[32] D. W. Boyd and J. S. W. Wong, "On nonlinear contractions," Proceedings of the American Mathematical Society, vol. 20, pp. 458-464, 1969.

[33] B. E. Rhoades, "A comparison of various definitions of contractive mappings," Transactions of the American Mathematical Society, vol. 226, pp. 257-290, 1977. 


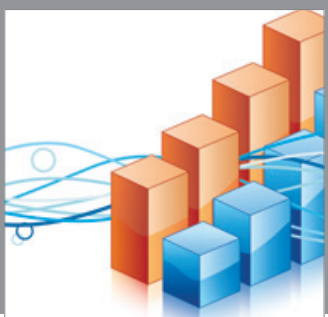

Advances in

Operations Research

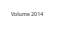

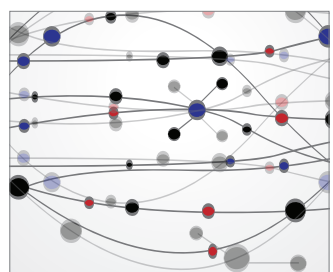

\section{The Scientific} World Journal
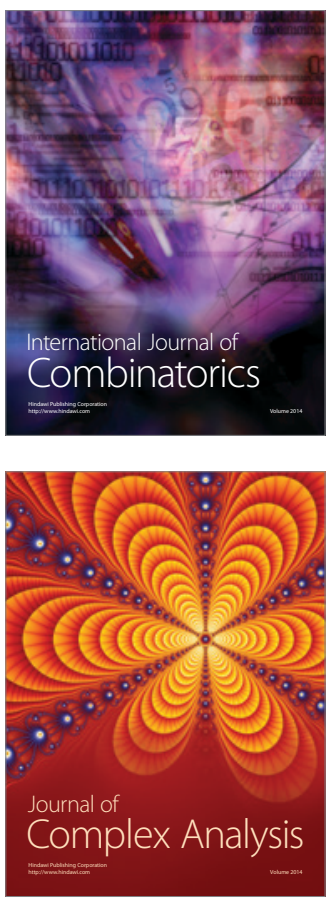

International Journal of

Mathematics and

Mathematical

Sciences
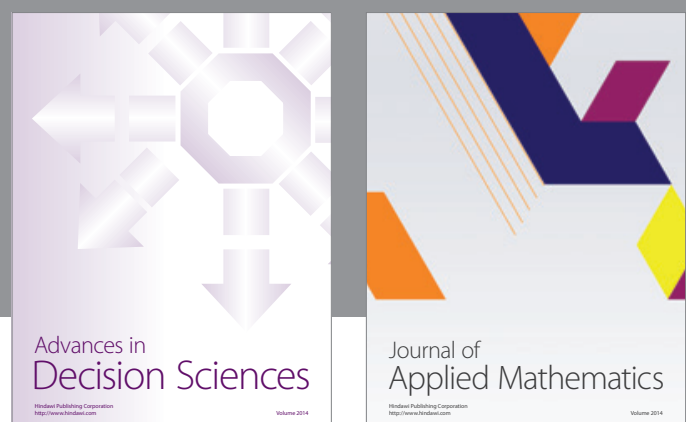

Journal of

Applied Mathematics
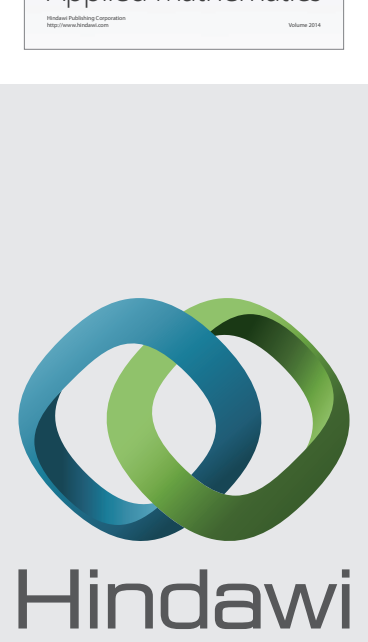

Submit your manuscripts at http://www.hindawi.com
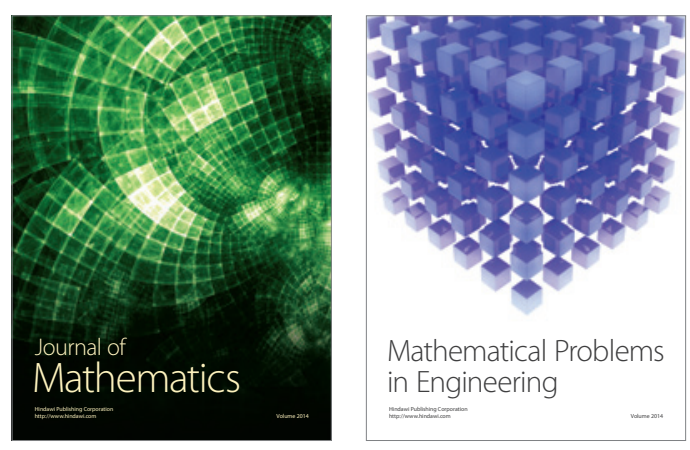

Mathematical Problems in Engineering
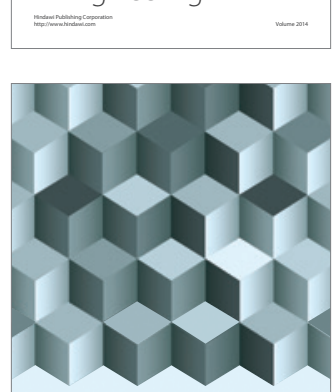

Journal of

Function Spaces
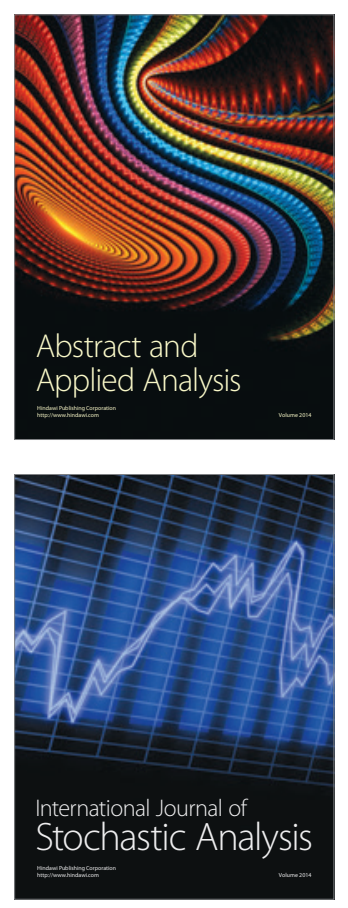

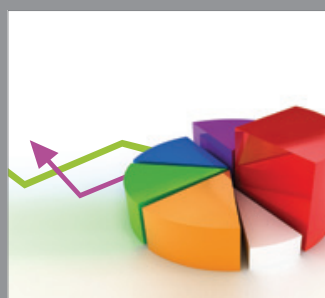

ournal of

Probability and Statistics

Promensencen
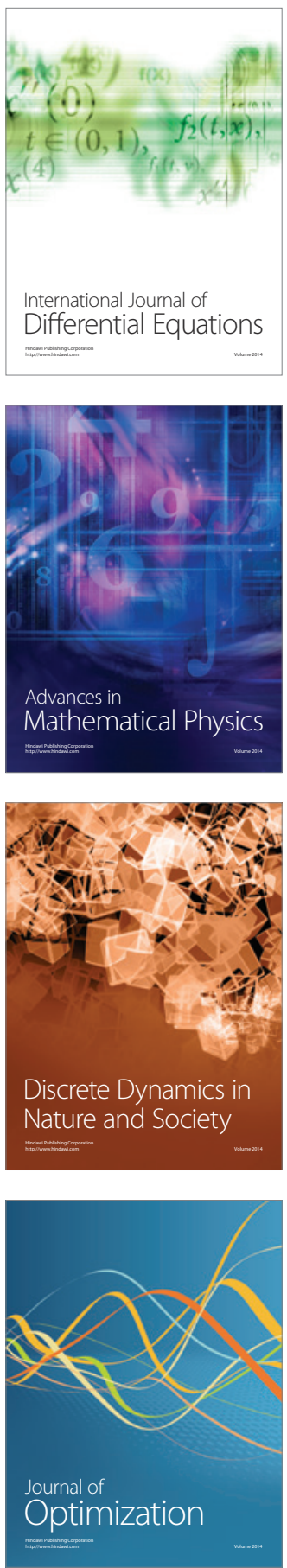